\title{
DISTRIBUTION AND FLIGHT ACTIVITY OF THE MONTEREY PINE APHID IN NEW ZEALAND
}

\author{
A.R. FLYNN ${ }^{1}$, D.A.J. TEULON ${ }^{2}$ and M.A.W. STUFKENS ${ }^{2}$ \\ ${ }^{I}$ National Plant Pest Reference Laboratory, Ministry of Agriculture and \\ Forestry, PO Box 2095, Auckland \\ ${ }^{2}$ Crop \& Food Research, Private Bag 4704, Christchurch \\ Corresponding author: flynna@maf.govt.nz
}

\begin{abstract}
The Monterey pine aphid (Essigella californica (Essig)) was first detected in New Zealand in 1998. It is native to North America and has recently extended its distribution to Europe, South America, Australia and New Zealand. This paper presents New Zealand distribution data from surveys undertaken after its detection in 1998. Flight data from aphid suction traps and a review of the hosts of MPA are also presented. MPA is recorded from the North Island and the top half of the South Island. Recorded hosts include several species of Pinus and Pseudotsuga menzieii. The main period of flight activity occurs between January and April.

Keywords: Monterey pine aphid, Essigella californica, distribution, flight period, Pinus radiata.
\end{abstract}

\section{INTRODUCTION}

The presence in New Zealand of the Nearctic aphid Essigella californica (Essig) (Hemiptera: Aphididae) the Monterey pine aphid (MPA) was confirmed on 25 March 1998 on Pinus radiata D. Don, the Monterey or radiata pine. This find was the result of an investigation undertaken by the Ministry of Agriculture and Forestry (MAF) after a MPA specimen was intercepted in Australia on avocado fruit imported from New Zealand in February 1998 (Carver \& Kent 2000).

The Monterey pine aphid, MPA, is native to western North America and Mexico and possibly to Florida. It is one of 13 species of Essigella that feed on Pinaceae, predominantly on Pinus, but also on Pseudotsuga and Picea (Blackman \& Eastop 1994; Sorensen 1994). This aphid has recently been introduced into Europe, France (Turpeau \& Remaudiére 1990), Spain (Seco Fernández \& Mier Duarte 1992) and southern Brazil (de Carvalho \& Lazzari 2000). In March 1998 MPA was detected on Pinus radiata in Canberra, Australia, and soon after was found in all states (Carver \& Kent 2000; Anon 2002).

The only other lachnid aphid in New Zealand found on the genus Pinus is Eulachnus brevipilosus Börner. Although trials have shown E. brevipilosus can survive on Pinus radiata it has not been found on this species in the field, preferring instead $P$. contorta, P. densiflora, P. mugo, P. nigra, P. ponderosa and P. sylvestris (Zondag 1983).

MPA is olive-green in colour, the body is torpedo or cigar shaped and 1.5-2.0 mm long (Figs $1 \& 2$ ). The legs are long in relation to body length, with the hind legs approximately the same length as the body. The possession of five antennal segments, and bifid tarsal claws, easily distinguishes MPA from Eulachnus brevipilosus. MPA feeds singularly at the base of needles and can move rapidly when disturbed. Little is known of the biology of MPA. It undergoes both anholocyclic and holocyclic (at high altitudes) lifecycles in its native distribution in North America (Blackman \& Eastop 1994; Carver \& Kent 2000). No males or oviparae have been reported in New Zealand.

This paper details the distribution of MPA based on survey records, its host-plant range and the flight period recorded from suction trapping in New Zealand. 


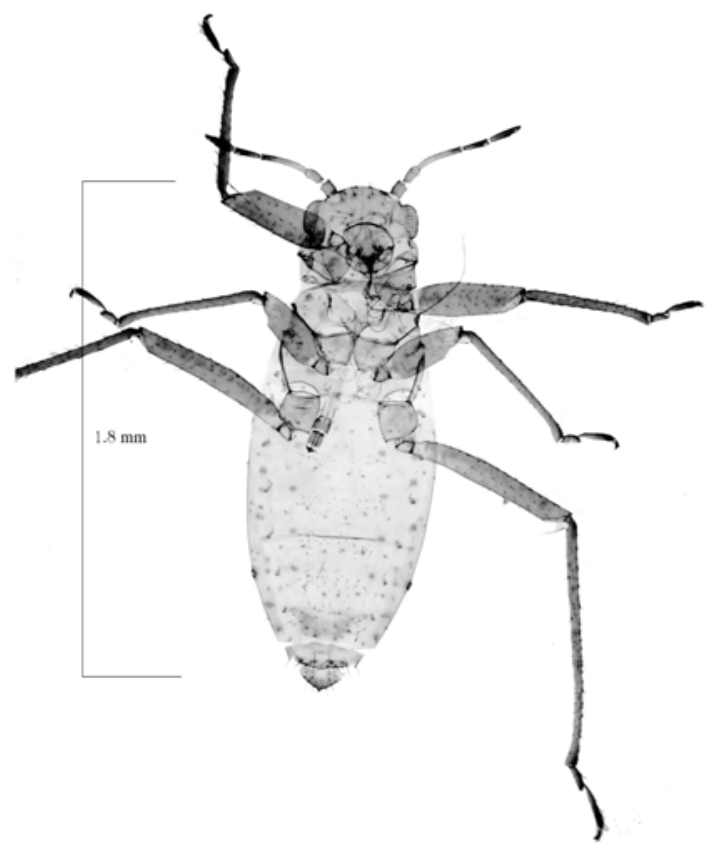

FIGURE 1: Apterous Monterey pine aphid (slide mounted).

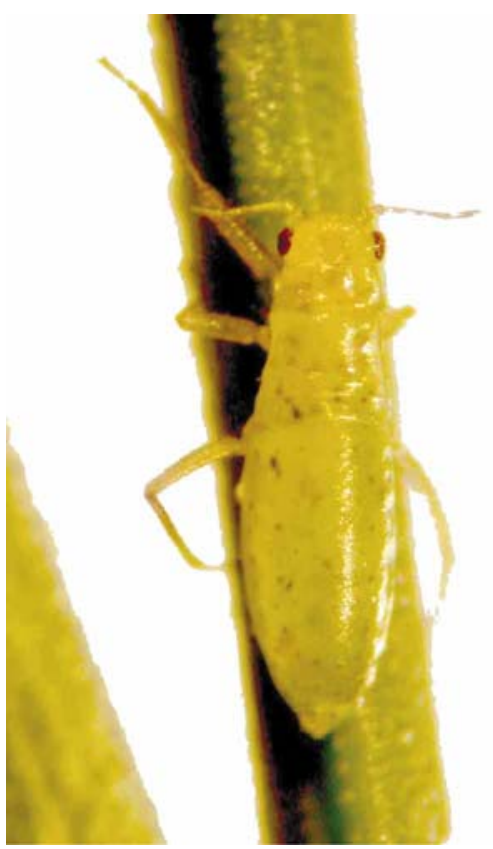

FIGURE 2: Monterey pine aphid on a radiata pine needle. 


\section{METHODS}

\section{Distribution and host range}

Initial survey work was undertaken by the MAF Plant Protection Centre (now MAF National Plant Pest Reference Laboratory). A much wider national survey of pine-growing areas was performed by MAF forest health advisors (now VIGIL forest health advisors, Forest Research). Much of this survey work was undertaken between April and June 1998, with additional distribution data up to 2002 collected as part of routine forest health checks (M. Ross, pers. comm.). The majority of specimen identifications were performed by Forest Research. Distribution and host record data were extracted from the Plant Pest Information Network (MAF) and Forest Health (Forest Research) databases.

\section{Suction trapping}

Suction traps at Ngatawara (Hastings, Hawke's Bay), Lincoln and Courtenay (both in Canterbury) were used to monitor MPA flight activity. The traps consisted of a $305 \mathrm{~mm}$ diameter aerofoil fan drawing approximately $60 \mathrm{~m}^{3}$ of air per minute through a long vertical metal tube, $7.5 \mathrm{~m}$ above the ground, which enabled aphids to be sucked into a jar at ground level. The Ngatawara suction trap was located on a vegetable grower's property near State Highway 50, close to Hastings, 40-60 km from the nearest radiata pine forests and was approximately $10 \mathrm{~m}$ above sea level. The Lincoln trap (approximately $10 \mathrm{~m}$ above sea level) was located at the Canterbury Agriculture Science Centre, approximately $14 \mathrm{~km}$ east of the nearest radiata pine forest. The Courtenay trap (approximately160 m above sea level) was located approximately $5 \mathrm{~km}$ south of the Eyrewell forest.

Only the Lincoln suction trap operated continuously from 1998-2003 with the other traps running an average of 8.2 months (Hastings) and 9.8 months (Courtenay) per year. The traps were emptied at weekly intervals and the aphids counted and identified.

\section{Distribution and host range}

\section{RESULTS}

MPA was recorded throughout the North Island within the first few months of its detection in April/May 1998 (Fig. 3). In the South Island (Fig. 3), MPA was detected in December 1998 and large numbers were collected from suction traps at Lincoln and Courtenay, Mid Canterbury (MC), in February 1999 (Fig. 4). It was recorded in other South Island regions including North Canterbury (NC), South Canterbury (SC) and Nelson (NN) in May 2000 and Buller (BR) in March 2001. The southernmost record is from Geraldine, South Canterbury (SC). The two letter area codes in parentheses refer to the regions described by Crosby et al. (1976).

Recorded hosts include Pinus radiata, $P$. pinaster, $P$. michoacana, $P$. muricata, $P$. montezumae, $P$. pinea, $P$. patula and Pseudotsuga menzieii. The most common host record is $P$. radiata, which reflects its wide planting and availability as a host.
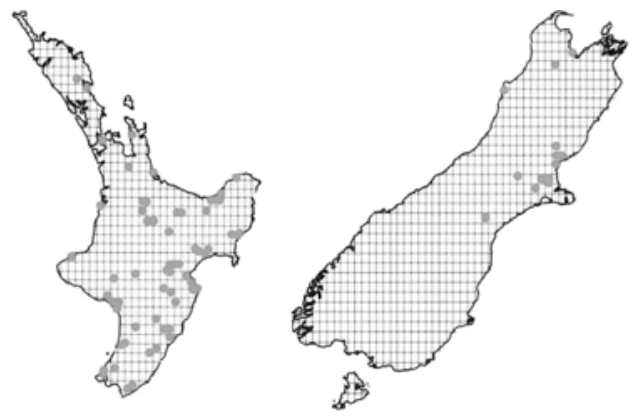

FIGURE 3: Distribution of Monterey pine aphid in New Zealand 1998-2002. 


\section{Suction trapping}

Monthly totals for MPA catches in suction traps are detailed in Figure 4. Trends in aphid flight patterns were similar at all sites over the five seasons of trapping. Very few aphids were caught from July to September with the main period of flight activity occurring between January and April. At times of peak aphid flight there were considerable differences in numbers caught in different years. The largest flights were at Courtenay in March 1999 (2592 aphids per month) and Ngatawara in March 2000 (999 aphids per month). Otherwise, numbers seldom exceeded 200 aphids per month.
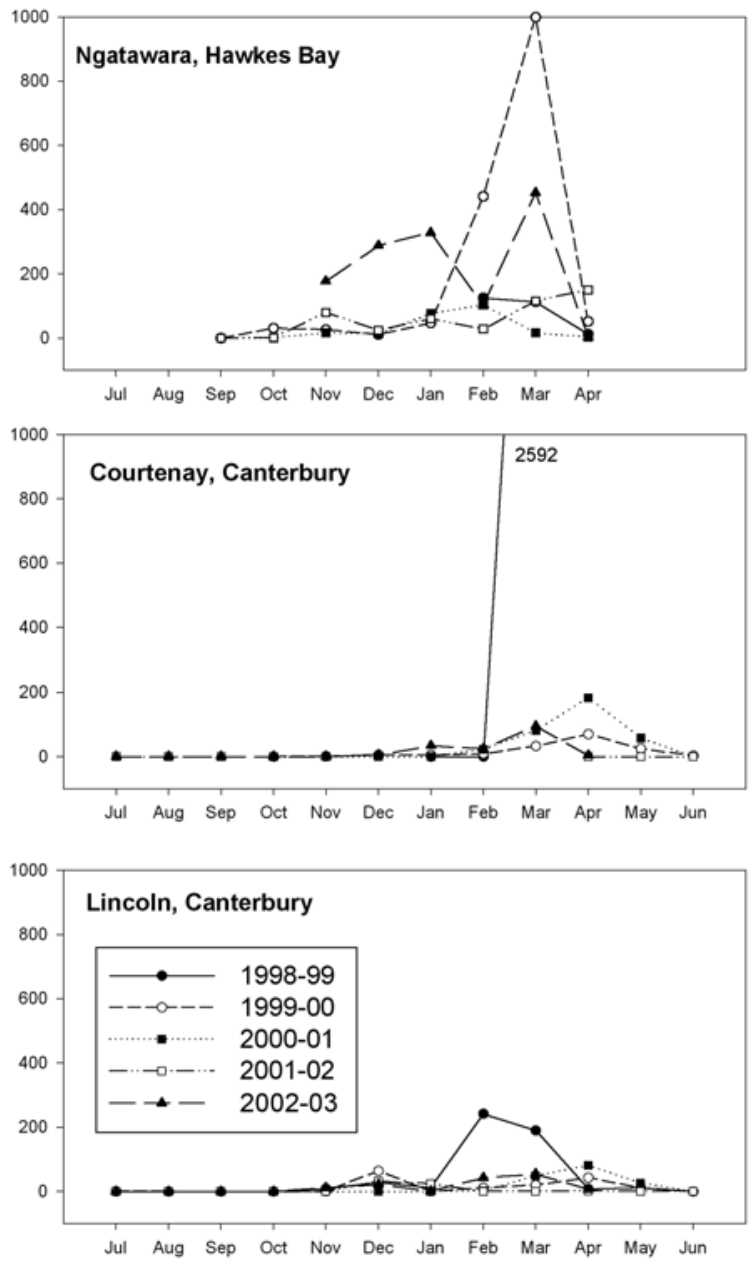

FIGURE 4: Total monthly catch of Monterey pine aphids from suction traps at Hastings, Courtenay and Lincoln, 1998-2003. 


\section{DISCUSSION}

The wide distribution of MPA recorded so soon after its initial detection suggests it may have already been in New Zealand for a few seasons. In addition, the wide availability of radiata pine may have also played a role in assisting successful establishment after dispersal episodes. In the South Island MPA does not appear in the Lincoln suction trap samples before 1998 so it is likely that MPA was not present in Mid Canterbury prior to this. Rapid dispersal may be linked to high population numbers as have been recorded for other aphid species during the first few seasons of colonisation (Teulon \& Stufkens 2002). Presumably, the dispersal of MPA throughout New Zealand was through natural factors (e.g. wind) rather than through human activity as seems to be the case with the lettuce aphid (Stufkens \& Teulon 2003). Although there appear to be no collection records south of Buller and South Canterbury (R. Thum, pers. comm.), given that MPA is found at relatively high latitudes in North America (British Columbia, Alberta) (Sorenson 1994) it is likely that MPA will be found throughout the South Island.

It is not certain whether MPA was present in Australia before New Zealand, and its entry pathway remains unknown. Possible entry pathways include wind dispersal across the Tasman Sea, as proposed for other aphid species (Close \& Tomlinson 1975), and contamination of imported product. Increased air travel between Australia, Europe and North America makes the latter possibility plausible.

An interesting feature of the suction trap data is that, like foliage sample data (Teulon et al. 2003; Appleton \& Gresham 2003), numbers varied between sites and years but peak numbers occurred in late summer/early autumn. This late season abundance is interesting because most other conifer inhabiting aphid species have population peaks in spring and summer with a crash in late summer (Teulon et al. 2003). Reasons for the MPA late season flight activity are not obvious and it would be interesting to investigate the role of climate and population density prior to production of winged morphs.

This aphid is of no economic importance in its native range (Carver \& Kent 2000). In Australia, increased defoliation on P. radiata has been linked to MPA feeding (Kent \& Carnegie 2000) and a relationship has been suggested between drought stress and Essigella needle cast (Anon. 2000). In New Zealand, damage appears to be limited to some needle yellowing at high density, and significant needle drop has not been recorded (Appleton \& Gresham 2003; Teulon et al. 2003). However Teulon et al. (2003) suggest MPA may contribute to tree stress through depletion of carbohydrate resource in the roots, which in turn reduces timber yields and contributes to disease susceptibility. Long term studies assessing growth on trees treated with systemic insecticides to provide a comparison between trees with and without MPA would help determine the economic impact of this aphid.

\section{ACKNOWLEDGEMENTS}

We thank Lindsay Bulman for providing data from the forest health database; VIGIL forest health advisors, especially the late Colin Barr, for collecting field data; Clive Appleton, Victor Eastop and Mary Carver for identification services; and Mark Ross for providing background information. We also thank Callum Fletcher and Georgia-Rose Travis for assisting with MPA suction trap samples.

\section{REFERENCES}

Anon. 2000: A new introduction to Tasmania. In: Doyle, R. ed. Forest Health Bulletin, Forestry Tasmania, Hobart, Tasmania 3: 1-2.

Anon. 2002: Tackling a damaging pest of Radiata. Onwood, No. 36. Commonwealth Scientific and Industrial Research Organisation. www.ffp.csiro.au/publicat/onwood/ onwood36 (3/3/2003).

Appleton, C.; Gresham, B. 2003: Monitoring of MPA populations in the Bay of Plenty forests Rotoehu and Kaingaroa. N.Z. Plant Prot. 56: 45-50. 
Blackman, R.L.; Eastop, V.F. 1994: Aphids on the World's Trees: An Identification and Information Guide. CAB International and The National History Museum, Wallingford, UK. 986 p.

Carver, M.; Kent, D.S. 2000: Essigella californica (Essig) and Eulachnus thunbergii Wilson (Hemiptera: Aphididae: Lachnidae) on Pinus in south-eastern Australia. Aust. J. Entomol. 39: 62-69.

Close, R.C.; Tomlinson, A.I. 1975: Dispersal of the Grain Aphid Macrosiphum miscanthi from Australia to New Zealand. N.Z. Entomol. 6: 62-65

Crosby, T.K.; Dugdale, J.S.; Watt, J.C. 1976: Recording specimens localities in New Zealand: an arbitrary system of areas and codes defined. N.Z. Jour. of Zool.3: $69+$ map.

de Carvalho, R.C.Z.; Lazzarir, S.M.N. 2000: First record for the California pine aphid, Essigella (Essigella) californica (Essig) (Homoptera: Aphididae: Lachninae), in southern Brazil. Proc. Entomol. Soc. Wash. 102: 757-758.

Kent, D.; Carnegie, A. 2000: Distribution of MPA in New South Wales \& ACT. In: Collett, N.G.; Simpson, J.; Schoenborn, C. ed. A review of the current status of the Monterey Pine Aphid MPA (Essig.). Proceedings of a Workshop. Dept. Natural Resources and Environment, Heidelberg, Victoria, Australia. Pp. 22-29.

Seco Fernández, M.V.; Mier Durante, M.P. 1992: Presencia en Espana del pulgon verde de los pinos americanos: Essigella (Hom., Aphididae: Cinarinae). Boletin de al Asociacion Espanola de Entomologia 16: 255-256.

Sorensen, J.T. 1994: A revision of the aphid genus Essigella (Homoptera: Aphididae: Lachnidae): its ecological associations with, and evolution on Pinaceae hosts. Pan-Pacific Entomol. 70: 1-102.

Stufkens, M.A.W.; Teulon, D.A.J. 2003: Distribution and host range of the lettuce aphid in New Zealand and its effect on the lettuce industry. N.Z. Plant. Prot. 56: 27-32.

Teulon, D.A.J.; Stufkens, M.A.W. 2002: Biosecurity and Aphids in New Zealand. N.Z. Plant Prot. 55: 12-17.

Teulon, D.A.J.; Herman, T.J.B.; Davidson, M.M. 2003: Monitoring Monterey pine aphid in Hawke's Bay forests. N.Z. Plant. Prot. 56: 39-44.

Turpeau, E.; Remaudiére, G. 1990: Decouverte en France d'un puceron des pins Americans du genre Essigella. Comptes Rendus de l'Academie Agricole de France 76: 131-132.

Zondag, R. 1983: Eulachnus brevipilosus Börner (Hemiptera: Aphididae) Pine Aphid. Timber and Forest Insects in New Zealand, No 55. Forest Research Institute, Rotorua, New Zealand. 4 p. 